\title{
The Integrated Project ManuBuild of the EU
}

\author{
Thomas Bock, Prof.Dr.-Ing./Univ.Tokio \\ Chair for Building Realization and Informatics \\ Faculty of Architecture \\ Technical University Munich \\ Arcisstrasse 21, D 80333 Munich, Germany \\ Phone: +49892892 2100/+49892892 2101 \\ Fax: +49892892 2102 \\ e-mail: thomas.bock@bri.ar.tum.de
}

\begin{abstract}
:
A UK-led construction consortium, ManuBuild, representing ten European countries, has secured 10 million Euros of EU funding for a four year research programme, with a key focus on the supply of housing. It is the largest EU funding ever awarded to the industry and promises a step change from current modern methods of construction towards an era of inspirational, unconstrained design with ultra-efficient manufacture and industrial-style construction. Led by Corus Group (UK), the initiative is endorsed by the European Network of Construction Companies for Research and Development (ENCORD1) and in line with the European Construction Technology Platform (ECTP2) research agenda. In addition to the 10 million Euros of EU funding, the consortium will be putting forward an additional 40 million Euros. ManuBuild will complete demonstration projects across Europe, including two large residential buildings in Madrid (led by EMV3, the City Council of Madrid), a low-rise apartment building in Stockholm (led by NCC4) and a residential project and a healthcare or schools building in the UK (led by Taylor Woodrow Construction, TWC5).

This paper will show the latest development of a MANUBUILD project partner NCC for industrialized building component production in the most recent factory and on site factory in Europe.
\end{abstract}

Keywords: high prefabrication ratio, on site factory, ergonomic machinery, high productivity,

\section{SHORT OVERVIEW IN PREFABRICATION OF RESIDENTIAL HOUSING}

Due to the beginning industrialisation in the $19^{\text {th }}$ century the "migration into cities" took effect, leading to housing shortage in the growing cities. Achieving almost any type of product up to enormous machinery in the new industrial way, first ideas of low cost industrial fabrication of housing were conceived and realized.

In the beginning $20^{\text {th }}$ century architects started dealing with this topics, adding more architectural and structural quality, such as Walter Gropius" "Baukasten im Großen" (large-scale construction kit).

After World War II urgent needs for affordable partly temporary housing rose again, bearing new systems in wood, steel and concrete. But again most efforts were focused on low-budget and mainly fast solutions, resulting in a lasting bad reputation of prefabricated housing.

In the following decades innovative automated construction grew mostly apart from housing industry, till in the eighties the Japanese were the first to use these modern technologies for fighting price decline and unemployment in the building sector by adding quality, accuracy and adherence to schedules. They began to bring up computer assisted full automated assembly lines and deploy robots even on site, using high tech from different industrial branches without any reservations.

Modern prefabrication can be mainly separated in two types of produced elements:

The more common planar wall and ceiling units, mostly using framework (timber, steel), as well as solid designs in timber, concrete or even brick. Providing ductwork insulation and partly completed surfaces, they can easily be lined up parallel for transport.

The 3D units, starting from simple load carrying constructions with bracing up to room cells with complete piping behind finished surfaces. Mainly using steel and concrete to bring up nearly any desired shape, the products are far more bulky causing an more inefficient transport. In common they both have their limitation in its weight an its dimensions by the needs of transport, so the joint between the multiple elements, sealing façade, insulation and even ductwork has to be one focus for new inventions.

Like in other industries, full automated assembly lines establish, linked to a CAD/CAM system delivering individual construction data. Beginning at robot managed stocks, providing any type of "running meter" material according to the actual drawing, via full automated formwork and assembly boards even for high-tech installation, ending in computerized interim storage and loading of the completed elements.

\section{MATERIALS}

2.1 Timber

Timber is the most common material used for prefabricated residential housing, mostly used for planar wall and ceiling units. being a natural construction material to be found and worked up nearly everywhere in the world, it is easy to bring up frame or solid construction elements by joining "running meter" beams of any dimension together. In modern factories autonomous robots are managing the stock providing any type of timber according to the actual drawing. after cutting to length all parts are positioned 
onto a assembly board, where they are joint and if necessary retrofitted with panels, foils or insulation and ductwork.

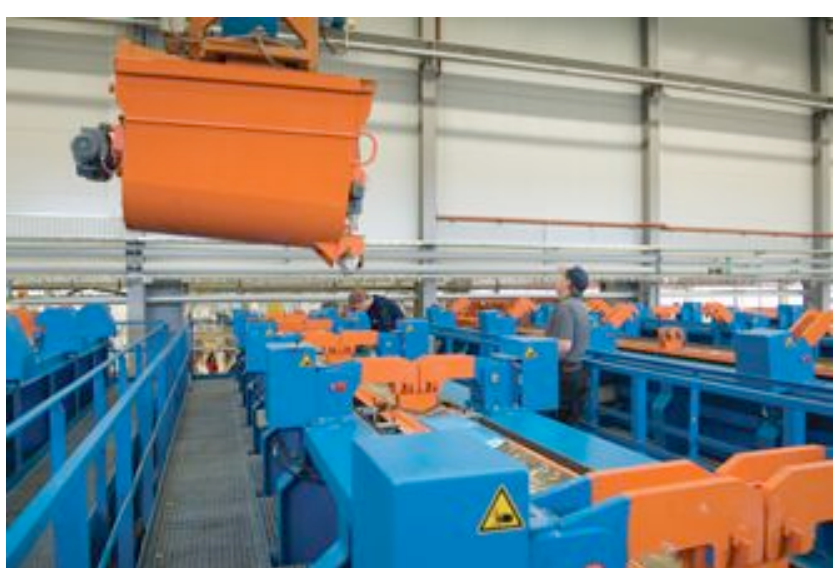

Concrete distribution at NCC factory

\subsection{Concrete}

Another common material in prefabrication is concrete. Although mostly being used for industrial construction and structural engineering, the benefits of the "liquid stone" can also be used in prefabricating almost any shape of domestic housing. Therefore mostly 3D modules are realized, only limited by its weight an its dimensions for transport. the production of concrete itself is mostly automated standard, and also the formwork, reinforcement and ductwork for planar and even 3D elements can be realised full automated by linking a CAD system providing full construction data.

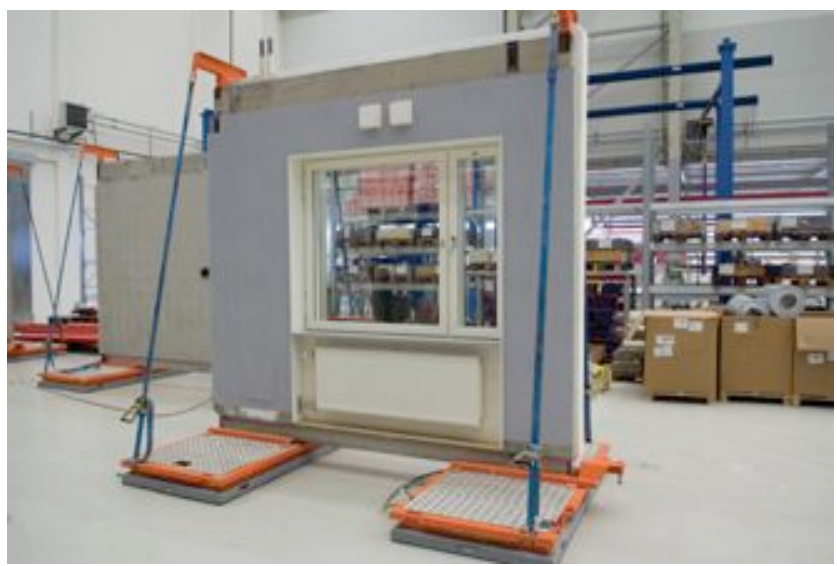

Concrete panel logistics in NCC factory

\subsection{Steel}

Steel can be used to bring up filigree load carrying construction, e.g. room modules or, in combination with any other material, prefabricated facades. Industry has access to a wide range of standardized semi-finished products such as beams or joints, whereby it is quite easy to bring up large quantities of prefabricated modules or units. Unlike other materials the construction companies have to deal with thermal bridges and, of course, fire prevention, making steel more suitable for larger well structurized industrial buildings and wide spanning modular construction systems than for small residential housing.

\section{MANUBUILD OVERVIEW}

The ManuBuild vision is of a future where customers will be able to purchase high quality, manufactured buildings having a high degree of design flexibility and at low cost compared to today. For the first time, inspirational unconstrained building design will be combined with highly efficient industrialised production.

ManuBuild targets a radical breakthrough from the current "craft and resource-based construction" to "Open Building Manufacturing", combining ultra-efficient (ambient) manufacturing in factories and on sites with an open system for products and components offering diversity of supply in the market.

- Customers are actively engaged in the design of their buildings, using state of the art interactive tools

- Mass customisation, not mass production, offers customers increased choice and design flexibility

- Ultra-efficient, flexible and scalable manufacturing enables production efficiencies of industrialised scale

- An open system for products and components gives diversity of supply and competitive costs for components

Enabling business processes, ICT systems, new materials and technologies and smart components etc will underpin this.

Potential impacts include significant reductions in the number of construction industry accidents, waste and the costs and time to construct buildings. This will allow Europe to improve it's building stock, whilst also releasing resources that can be allocated to other income generating industrial sectors.

\section{NCC Komplett production system}

In the NCC Komplett factory 60 operators work on job rotation time schedule. The yearly capacity is 1000 apartments and each worker is producing 17 apartments yearly. Automation and mechanization are ergonomically designed to reduce labour fatigue. Every 15 Minutes a truck leaves the factory. The apartments are $90 \%$ prefabricated. The investment was about 300 million SEK. The on site assembly factory is all weather proofed enabling ergonomic working conditions all year around. 


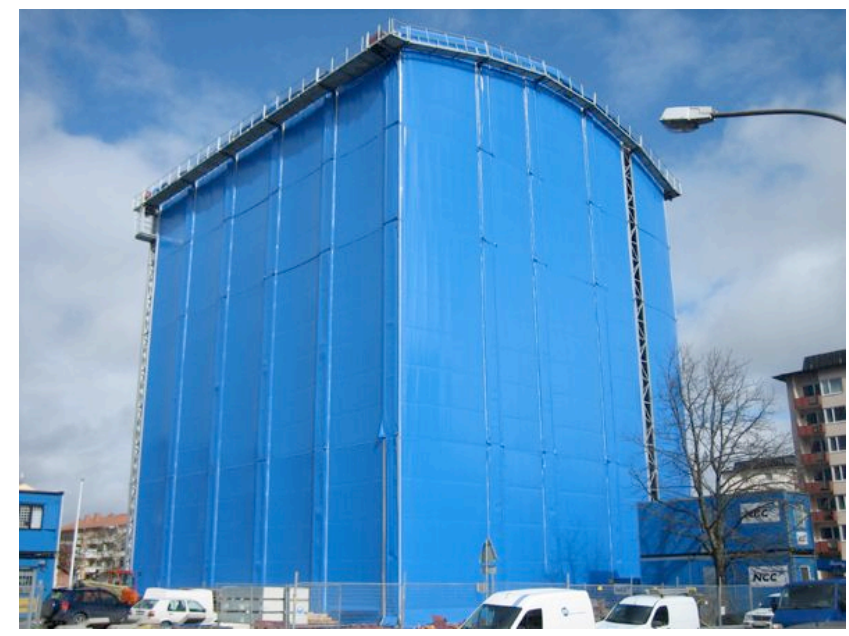

On site factory of NCC Komplett

\section{DESCRIPTION OF WORKPACKAGES}

5.1 WP1 Stakeholder requirements

This Work Package is meant to capture, organise, structure, prioritise and categorise stakeholder requirements: "Voice of the stakeholder" (including perspectives of LSE, SME, national \& international initiatives and technology platforms and of course the ECTP - European Construction Technology Platform). Further objectives are to continuously tracking and verification of the relevance of on-going work by and for the stakeholders.

\subsection{WP2 Building concepts}

Develop and introduce concepts, rules and new products for buildings that are suited for manufacturing:

- concepts, principles, guidelines and rules for flexible and highly customisable architecture,

- typological solutions and multi-level standardisation, (pre-)configuration strategies for the elements, components and systems forming the basis of the new architectural language and to establish a standardisation of living spaces based upon customer views and aspirations of space usage and scale. Ensure that this new space standardisation strategy is adopted by the industry on a European basis.

- new customer oriented design processes that are fully integrated with the advanced manufacturing of housing

- smart components, multi-function integrated modules,

- connections and interfaces,

- samples of building solution templates for customisation, standard(s) for open manufactured buildings and a Europe wide technical approval process for factory produced homes working in collaboration with EOTA and the insurance and financial industries.

5.3 WP3 Value driven business processes The objectives of WP3 is to develop:

- new value driven business processes for implementing the open manufactured building system;

- organisational concepts and models to support / reflect the new processes;

- new services covering the whole life cycle of buildings from design until demolition and recycling. the overall (integrated) business model for ManuBuild.

5.4 WP4 Ambient manufacturing methods

- $\quad$ Explore and assess new concepts and practices in factory production (for a flexible and market responsive capability) including fixed, mobile and site-based types bringing with the aim of radically improvements over the current 'cottage industry' approach to factory

- Develop new advanced manufacturing techniques to enable: a) closure of the industry capacity - consumer demand gap. b) step change improvements in quality and reductions in defect levels \& costs of rectification. c) increases in productivity and efficiency resulting in significantly lower costs. d) radically reduced lead times particularly from point of order to occupancy). e) step change improvements in health and safety of construction workers through better working environments and reduced accident rates.

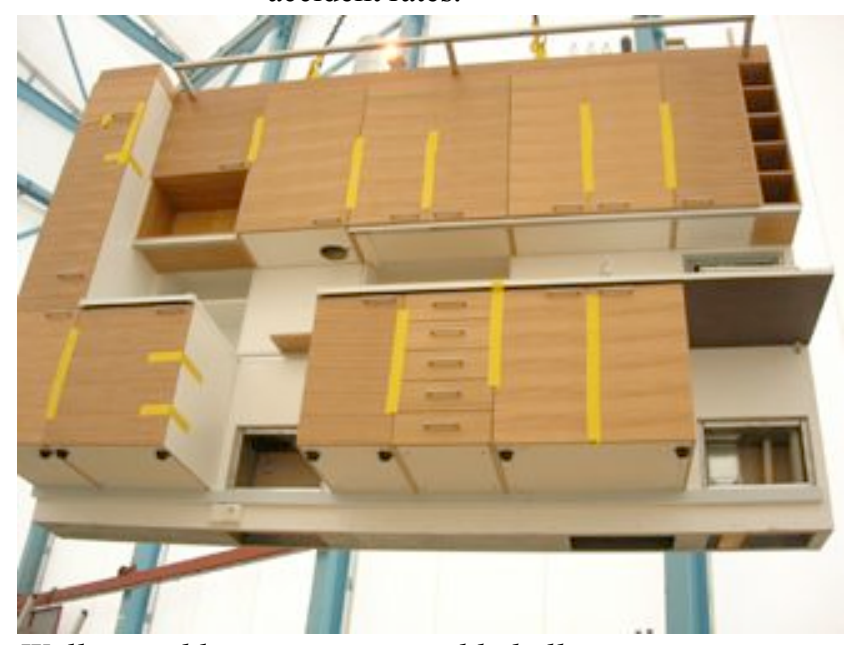

Wall assembly in on site assembly hall

ManuBuild System: component catalogues and tools for information delivery, design, market analysis, custom-configuration, logistics and 
5.5 WP5 ICT support

- Specify reference architecture for an integrated ICT platform for the ManuBuild System

- Develop new key ICT supporting the

5.6 WP6 Technical integration

- Develop input for decision making in the TC.

- Introduce the vision and strategy for open manufactured buildings (the "ManuBuild System").

- Establishing of the ManuBuild System concept, considering the developed solutions of the WPs 2, 3, 4, 5 and assure its integrity.

- Ensure S\&T quality of results and coherent RTD approach in the IP. Identify and assess technical risks, and suggest contingency measures (provide further support to the technical management of the project).

5.7 WP7 Protection and exploitation of knowledge

- Protect intellectual property of the knowledge resulting from the project.

- Prepare exploitation of results by partners.

- Promote take-up and exploitation beyond the consortium, especially by SMEs.

- Assess socio-economic impacts of the knowledge and technology generated, and the factors affecting exploitation (e.g. safety, role of women, standardisation, ethical aspects and regulations etc.).

5.8 WP8 Demonstrations

- To demonstrate the results of WP2-WP6 and key scenarios of ManuBuild.

- To prove the technical viability of new technologies applied across the whole lifecycle (from design to service and training).

- To validate the results within the commercial environments of high-profile "ManuBuild" projects (four real, physical full-scale buildings) including property

- NCC Komplett Building

- developments in Spain, UK and Sweden.

NCC Komplett Building

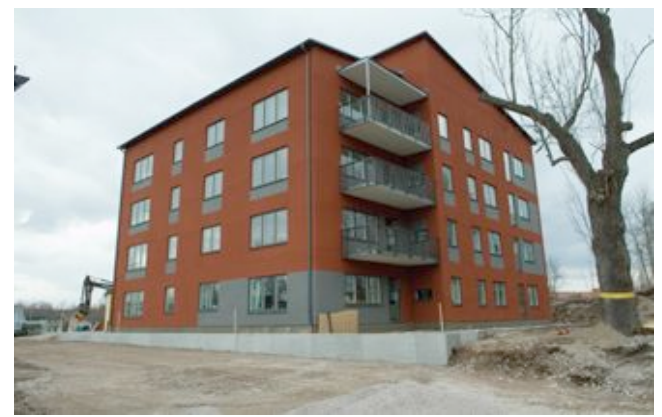

\subsection{WP9 Dissemination}

- Disseminate beyond the consortium the vision and results of ManuBuild.

- Promote the image of open manufactured buildings and raise the image of the construction industry in general.

- Liaise with key stakeholders in the ECTP, the industry and RTD communities and form consensus.

5.10 WP10 Training

The objective for the first 18 months in this WP is to develop training concepts for implementation after $\mathrm{m} 18$.

\subsection{WP11 Management}

Overall coordination and management of the Integrated Project. Management activities are organized in general project coordination, in the handling of all the financial and administrative issues and in its technical management. The specific objective of the first 18 months will be the one of establishing the complete management structure of the IP so to reach a regime situation within the first months of the research and to efficiently manage the project in this period of time.

\section{REFERENCES}

[1] www.manubuild.org

[2] www.ncc.se

[3] Newsletter 3, March 2006,

ManuBuild Open Building Manufacturing 